\title{
Mudança curricular: desafio de um curso de graduação em enfermagem*
}

\author{
Curricular change: a challenge for an undergraduate nursing course \\ Cámbio curricular: un desafío de un curso de grado en enfermería
}

\author{
Rosiele Pinho Gonzaga da Silva', Rosa Maria Rodrigues ${ }^{1}$ \\ 'Universidade Estadual do Oeste do Paraná, Curso de Enfermagem. Cascavel, PR
}

Submissão: $11 / 06 / 2007$

Aprovação: 12/12/2007

\section{RESUMO}

Apresentamos pesquisa Que pretendeu contribuir com a avaliação do Projeto Político Pedagógico (PPP) de um curso de graduação em enfermagem. Objetivamos analisar e discutir a reformulação curricular; contribuir com o processo de discussão e avaliação. O percurso metodológico se fez pela análise comparativa entre o PPP de 1995 e o de 2003 e por dados coletados com docentes e discentes acerca dos pressupostos teóricos do curso que foi o elemento inovador identificado no PPP de 2003. Os dados revelaram Que os pressupostos teóricos, em sua maioria têm orientado o processo de formação, mas Que ainda há conceitos pouco incorporados como o de interdisciplinaridade. Outro dado levantado foi a não efetiva participação de discentes e docentes no processo de implantação e avaliação do PPP.

Descritores: Educação Superior; Enfermagem; Currículo.

\section{ABSTRACT}

This work presents a research that intended to contribute with the evaluation of the Pedagogic Political Project (PPP) of an undergraduate nursing course. The objective is to analyze and to argue the curricular reformularization; contributing to the process of discussion and evaluation. The used methodology was the comparative analysis between the PPP of 1995 and 2003 and the data collected with professors and students concerning the theoretical presuppositions of the course that it was the identified innovative element in the PPP of 2003. The data revealed that the theoretical presuppositions, in your majority guided the formation process, but there are concepts that still little incorporate like the interdisciplinarity. Another raised data was the non-effective participation of students and professors in the process of implantation and evaluation of the PPP.

Descriptors: Education Higher; Nursing; Curriculum.

\section{RESUMEN}

Presentamos pesquisa que pretendió contribuir con la avaliacion de lo Proyecto Politico Pedagogico (PPP) de uno curso de grado en enfermería. Objetivamos analisar y discutir la reformulacion curricular; contribuir con el processo de discusión y avaliacion. El percurso metodológico se ha hecho por la analise comparativa entre el PPP de 1995 y el de 2003 y por dados colectados con alumnos y mestres acerca de los presupuestos teóricos del curso que fue el elemento innovador identificado en el PPP de 2003. Los dados revelaran Que los presupuestos teóricos, em su mayoria tem orientado el proceso de formacion, pero que aún haya conceitos pocos incorporados con el de interdiciplinaridad. Otro dado levantado fue la no efectiva participación de alumnos y mestres en el proceso de implantación y avaliación del PPP.

Descriptores: Educacion Superior; Enfermagem; Curriculo. 


\section{INTRODUÇÃO}

O trabalho analisa a reforma curricular implantada no ano de $2003 \mathrm{em}$ um curso de enfermagem em uma universidade estadual na Região Oeste do Paraná Que iniciou a primeira turma em 1999. Os registros sobre sua história informam Que o curso foi organizado a partir das necessidades sentidas em âmbito nacional, para a expansão das escolas de nível superior, dentre elas as escolas de enfermagem.

Sua trajetória foi marcada pela preocupação com a formação Que pode ser identificada nas Quatro reorientações curriculares experimentadas nos 20 anos completados em 1999(1). Elas aconteceram por Questões internas, bem como por exigências legais desencadeadas pelas políticas centrais de formação de nível superior.

Percebemos que sua história guarda estreita relação com os acontecimentos políticos e econômicos da região e do país, contudo, a configuração interna dessas alterações mostra, em alguns momentos, certa inobservância da lei o Que avaliamos como positivo em alguns aspectos, como na incorporação da formação generalista do enfermeiro Quando esta dimensão estava apenas no discurso ${ }^{(1)}$.

Apesar dessa intencionalidade, tais princípios nem sempre se efetivaram com predomínio da assistência hospitalar curativa, alertando-nos Que, além do discurso há Que se pensar formas ou estratégias de efetivá-los.

No ano de 1995, um novo currículo foi elaborado e direcionou a formação até 0 ano de 2003 Quando, após 2 anos de discussão entre os docentes e discentes foi submetido à reformulação e proposição de um novo projeto político-pedagógico (PPP) Que se encontra em fase de implementação e avaliação. Neste sentido, esta pesquisa de iniciação científica orientou-se para a discussão da mudança, na perspectiva dos sujeitos envolvidos visando contribuir com a formação, porém não substituindo o processo de discussão coletiva desencadeado pelo curso.

\section{OBJETIVOS}

- Analisar e discutir a reformulação curricular desencadeada no ano de 2003, em um curso se enfermagem na Região Oeste do Paraná;

- Contribuir com o processo de discussão e avaliação em andamento desde a implementação da proposta de reforma curricular.

\section{METODOLOGIA}

No primeiro momento da investigação realizamos a análise comparativa entre o projeto político pedagógico implantado em 1995 e o implantado em 2003. Para a sistematização dos dados utilizamos como recurso a leitura comparativa dos referidos projetos e nela fomos identificando pontos de divergência, convergência e mudanças.

Após esta análise em Que defrontamos os dois documentos (PPP de 1995 e PPP de 2003), dentre as muitas Questões Que poderiam compor o segundo momento de investigação, direcionamos a atenção aos pressupostos teóricos Que identificamos como mais elaborados no PPP de 2003. Justificamos a escolha no entendimento de que é preciso investigar em Que medida os pressupostos enunciados no PPP estariam sustentando a ação docente.

Para organizar o formulário de coleta exploramos os seguintes conceitos presentes nos pressupostos teóricos do curso: saúde/ doença, interdisciplinaridade, humanização, homem, trabalho, processo de trabalho, enfermagem, enfermeiro, formação generalista, crítica e reflexiva Que compuseram o formulário de coleta de dados aplicado aos sujeitos da pesquisa. A partir desta definição o projeto foi submetido à apreciação do Comitê de Ética em Pesquisa da Unioeste, conforme previsto na Resolução 196/ 1996 do Conselho Nacional de Saúde no Que se refere à pesquisa envolvendo seres humanos e aprovado pelo parecer 078/2006CEP.

O total de sujeitos participantes foi de 3 I ( I I docentes e 20 discentes). Todos os sujeitos leram e assinaram o termo de consentimento livre e esclarecido em atendimento à resolução 196/96 do Conselho Nacional de Saúde.

A amostra docente foi constituída por todos os docentes Que procederam a devolução dos formulários preenchidos. O período de coleta com os docentes foi de um mês. Do total de 30 formulários depositados em suas pastas obtivemos o retorno de I I , sendo esta, então a amostra docente submetida à análise.

A amostra discente foi determinada por sorteio aleatório a partir da lista de matrícula da secretaria acadêmica solicitada via ofício. Sorteamos Quinze alunos da terceira e Quinze alunos da Quarta série. Mesmo após várias tentativas de recuperação dos formulários conseguimos reunir apenas vinte, dez da terceira série e dez da Quarta série. Os demais foram devolvidos sem preenchimento com a justificativa de Que não tiveram disponibilidade para responder.

Os dados foram sistematizados e analisados conforme o conteúdo das informações fornecidas agrupando aQuelas falas Que se aproximaram em convergência de conteúdo em unidades temáticas.

\section{RESULTADOS E DISCUSSÃO}

\section{Avaliando a Reforma Curricular na Internalidade do Curso de Enfermagem}

A partir das discussões iniciadas em 2001 para o estudo e proposição de um novo PPP para o curso organizou-se um currículo disciplinar com cinco anos de formação e Que mantém a licenciatura articulada à sua estrutura.

Da análise comparativa entre o PPP de 1995 e o de 2003 foi possível verificar algumas mudanças no Que se refere à carga horária das aulas teóricas, APS (aulas práticas supervisionadas) e aulas práticas (aulas de laboratório); exclusão e inclusão de disciplinas, desmembramento, remanejamento de série e alteração dos conteúdos.

Assim, é possível afirmar Que, no Que tange a estrutura curricular ou ao marco estruturaL ${ }^{(2)}$,o curso de enfermagem manteve a estrutura disciplinar seguindo sua tradição.

Em texto preliminar a esta pesquisa mostramos Que, no Brasil, algumas reformas curriculares têm se encaminhado para adoção de currículos integrados, alguns até rompendo com a idéia de disciplina. Não é o caso do curso de enfermagem estudado Que mantém a concepção pedagógica centrada no conhecimento e tendo o professor um papel nuclear na condução da aprendizagem. 
Da análise comparativa entre os dois documentos privilegiamos o aprofundamento nos pressupostos teóricos. Tal "escolha" está sustentada no entendimento de que eles deveriam dar organicidade estrutural ao projeto assim como nortear a prática docente no "chão da sala de aula".

A partir da análise dos PPPs podemos afirmar Que os pressupostos teóricos do PPP de 2003 foram mais claramente explicitados e adQuiriram maior elaboração comparado-se com 1995. Isso pode ser verificado na introdução e abordagem dos conceitos de trabalho, homem, humanização, saúde/doença, processo de trabalho, enfermagem e interdisciplinaridade. Ao mesmo tempo, alguns pressupostos se mantiveram e, além de não serem abandonados deixaram de ser enunciados genéricos constituindo-se em conceitos e concepções claras, objetivas Que deveriam ser contemplados nas ementas das disciplinas, visando à formação do profissional enfermeiro dentro do perfil almejado.

Deste modo seria imprescindível Que as ementas das disciplinas estivessem afinadas com os pressupostos do PPP para a construção de um profissional "crítico e reflexivo", integrado com as necessidades da população, perfil epidemiológico e com as transformações sociais, seja na área da saúde e/ou educação ${ }^{(3)}$.

Este entendimento é o Que buscamos mostrar abaixo em uma comparação entre as formulações teóricas do curso e aQuelas Que se encontram expressas nas ementas das disciplinas do projeto político pedagógico.

Assim, analisando o PPP de 2003 de forma comparativa com o PPP de 1995, percebe-se naquele um maior enfoque na enfermagem como prática social, na formação de um profissional generalista compromissado com as demandas da população e com a docência.

Na ementa da disciplina de Psicologia da Educação, por exemplo, se faz referência ao "fornecimento de subsídios e respaldo teóricometodológico para uma atuação docente Que responda de forma transformadora a realidade sócio-educacional”(3).

Outro aspecto mais explícito no PPP 2003 refere-se a formação de um enfermeiro que atue de modo crítico e reflexivo, entendendo o processo saúde-doença além do aspecto biológico, Que o considere como resultado de múltiplos determinantes sociais, econômicos e culturais. Além disso, para Que tenha competência e habilidade para intervir nos problemas de saúde prestando sua assistência com Qualidade e compromisso. Isto pode ser observado na ementa da disciplina Saúde, Trabalho e Ambiente, em que "Saúde e doença são consideradas como expressão das condições concretas de existência. A relação entre trabalho, saúde, ambiente e sociedade”(3). na ementa da disciplina de Enfermagem em Puericultura, Criança e Adolescente Sadios e Criança e Adolescente Hospitalizados que trata da "compreensão epidemiológica, social, familiar e política dos problemas de saúde da criança e do adolescente hospitalizado"(3). Na ementa de Administração em Enfermagem em Que se aborda Que as "funções administrativas e a caracterização das necessidades da clientela, são baseadas em perfil epidemiológico local [...]"(3). Em Enfermagem em Ginecologia e Obstetrícia em que se tem a "compreensão epidemiológica, social e política dos problemas de saúde da mulher e da gestação" como indicações a serem abordadas na disciplina" (3).

Em metodologia científica verifica-se a abordagem dos "conceitos, métodos e instrumentos de análise do conhecimento e de sua produção dentro de uma perspectiva histórica"(3). Daí a consideração do homem como um ser social ao mesmo tempo entendendo Que seus conhecimentos são historicamente construídos e acumulados ao longo do tempo, tornando-se pertinente o conhecimento do contexto social, de sua realidade para a compreensão do processo saúde doença, reafirmando os pressupostos teóricos do PPP.

A ação docente também é enfocada, como pode ser evidenciado pelas ementas das disciplinas Didática Aplicada à Enfermagem e Prática de Ensino: "Estrutura e elemento do processo de ensinoaprendizagem. Pressupostos do trabalho interdisciplinar no processo educativo e diferentes técnicas de ensino"(3). "Atividade teórico-prática Que visa à reflexão e a investigação da ação docente, bem como da atuação docente sistematizada em cursos específicos de formação de profissionais de enfermagem, bem como o desenvolvimento de práticas educativas em saúde”(3).

A pesQuisa e a produção de conhecimento ganharam um maior espaço no atual PPP, visto Que o curso tem entre seus objetivos a promoção e desenvolvimento de projetos de extensão e pesQuisa contribuindo para a produção de conhecimento e entendimento da realidade, visando a ampliação do atendimento público à saúde da população em todos os níveis de atenção; Instrumentalizar os alunos para desenvolver atividades de iniciação cientifica; Produzir conhecimentos científicos como instrumentos para o desenvolvimento profissional"(3).

Pelo exposto é possível concluir Que houve a preocupação em materializar os pressupostos teóricos na estruturação das disciplinas e, por conseguinte dar coerência ao processo de formação explicitado em seus pressupostos teóricos.

Enfim, cabe agora identificar, como eles têm se materializado na atuação docente e discente sendo este o próximo momento desta pesquisa no eual, a partir da fala de docentes e discentes buscaremos correlacionar os conceitos explícitos no PPP com aQueles vivenciados efetivamente por docentes e discentes na relação ensino aprendizagem.

\section{Os Pressupostos Teóricos na Voz dos Discentes da Terceira e Quarta Séries}

As Questões Que compuseram o formulário de coleta de dados foram pautadas nos conceitos dos pressupostos teóricos contidos no Projeto Político Pedagógico do curso de Enfermagem assim formuladas: 1) Fale sobre a concepção de saúde/doença Que você tem vivenciado na sua trajetória acadêmica; 2) Como você tem percebido a interdisciplinariedade na atuação docente e na organização curricular do curso de enfermagem; 3) Como a humanização da atenção à saúde e o conceito de homem tem aparecido em sua formação acadêmica (dê exemplos); 4) Partindo dos conhecimentos Que você adQuiriu até o momento em sua formação, como você definiria a enfermagem e o enfermeiro (a); 5) $\mathrm{O}$ Que significa, em seu entendimento, uma formação generalista, crítica e reflexiva; 6) Como você tem vivenciado o processo de avaliação do atual Projeto político Pedagógico e Que ações você considera necessárias para Qualificar a avaliação.

O conceito de processo saúde/doença expresso pelos acadêmicos se aproxima ao conceito do PPP, principalmente no Que se refere àanálise deste processo, em Que se deve previamente ter o conhecimento do modo como a sociedade se organiza, do 
ambiente em Que o individuo está inserido não decorrendo de uma escolha pessoal, em Que o individuo é o único responsável pelo seu estado de saúde, mas adouire aspecto social, abrangente, resultado da influência de inúmeros determinantes Que agem sobre o sujeito e sobre os Quais ele age.

A convergência do conceito saúde/doença entre o adotado pelo PPP e discentes é relevante, uma vez que demonstra Que o conceito está inserido na atuação docente e Que pode contribuir, de fato, para a formação do profissional enfermeiro, não se reduzindo apenas ao conteúdo teórico e estão incorporando e relacionando na prática com problemas vivenciados pela população ainda na academia.

Quanto à presença da interdisciplinaridade observaram-se divergências nas falas dos discentes, pois aparece para alguns como prática freqüente entre todos os professores, para outros, os docentes até tentam atuar em conjunto, mas as opiniões se divergem e o trabalho fica dificultado não ocorrendo articulação entre as disciplinas, sendo esta a resposta mais freeüente do Que aQuelas Que afirmam ser uma prática adotada por todos; outros dizem Que alguns professores tendem a focar mais a sua área e a maioria das disciplinas não se relacionam. Outro ponto a ser destacado é a interdisciplinaridade na organização curricular, Que aparece na maioria das falas como desorganizada, não existindo relação entre algumas disciplinas. Por outro lado há falas Que elogiam a disposição das matérias e que até serve de exemplo para os demais cursos da área da saúde da instituição.

Segundo as falas dos discentes a humanização na assistência está enfatizada em todas as disciplinas, e as respostas convergiram para uma ação Que envolve respeito por valores, crenças, características individuais e Que também abrange resolutividade de problemas, organização política e social. Em comparação com o conceito propugnado no PPP percebe-se Que não se afasta dele, principalmente no Que se refere ao fato de estar pautado pelo respeito, pela solidariedade e pelo desenvolvimento da autonomia e da cidadania dos profissionais e usuários envolvidos"(3).

Destaca-se também que para alguns alunos o cuidado já é humanizado por natureza, uma vez Que o mesmo está sendo prestado de um ser humano para outro, se tornando um pleonasmo a referência a assistência humanizada.

Quanto ao conceito de Homem abordado pelos discentes evidenciou-se um discurso generalizado definindo-o como ser pensante; Que sofre influência do meio; um ser social; criador da história; Que modifica a natureza e Que deve ser visto holisticamente dentro de seu contexto. Estas características se assemelham ao proposto no PPP em Que o homem é entendido como um "ser histórico-social, Que sente, pensa, elabora concepções e planos, transforma a natureza, desenvolve sua sociabilidade cria linguagem, símbolos e instrumentos com os Quais reproduz relações sociais, transforma e repassa a cultura [...]"(3).

No processo de análise dos dados referentes à concepção de enfermagem percebemos, pelas falas dos alunos, Que a consideram como uma profissão, uma arte, uma ciência, um trabalho Que objetiva a prestação do cuidado seja em hospital, saúde pública ou coletiva. Ao mesmo tempo em Que o enfermeiro é referenciado como um educador, um administrador, um coordenador de equipe que organiza suas ações visando à promoção da saúde. Desse modo há coerência entre a concepção dos alunos e o PPP, uma vez Que neste a enfermagem é abordada eneuanto prestação do cuidado, profissão, prevenção de enfermidades, promoção e recuperação da saúde, Que soma saberes advindos de outras ciências. E o enfermeiro é compreendido como um dos agentes do processo de trabalho em saúde com formação generalista e humanista atuando de forma crítica e reflexiva, com competência técnica, científica e política Que intervém sobre os problemas/situações de saúde/doença e em seus determinantes com responsabilidade social e no compromisso com a promoção da saúde integral do ser humano e com a Educação Básica e Educação Profissional em Enfermagem”(3).

No entendimento dos discentes, a formação generalista compreende o recebimento de conhecimentos gerais e conceitos básicos, Que abordam Questões sob várias visões, Que tem Qualificação e o mínimo de conhecimentos para o exercício da profissão em QualQuer espaço de atuação profissional.

Quanto à formação crítica e reflexiva as respostas convergiram à reflexão, Que significaria não ser submisso; não concordar com o Que está sendo imposto sem antes discutir e conhecer direitos; através da lógica e razão identificar as necessidades e soluções para problemas Que acometem o paciente e a sociedade e a capacidade de formular uma opinião a partir do repasse de conhecimento.

Comparando o PPP do curso Que entende formação generalista como "ter consistentes conhecimentos Que lhe permitam desempenhar o trabalho da enfermagem nos principais espaços de atuação profissional [...] sem partir para habilitações precoces Que descaracterizam o princípio básico da formação na graduação"(3); e a compreensão de formação crítica e reflexiva como "a capacidade de diagnosticar e comprometer-se com a busca de soluções dos problemas de saúde, de comunicar-se, de tomar decisões, de intervir no processo de trabalho, de trabalhar em equipe e de enfrentar situações de constantes mudanças" ${ }^{(3)}$, percebemos uma convergência de falas dos discentes com o expresso no PPP.

Quanto à avaliação do atual Projeto Político Pedagógico do curso e ações consideradas necessárias para Qualifica-la, a maior parte dos discentes não respondeu informando Que não tinham conhecimento do processo e não iriam opinar. Outros, entretanto, mesmo não participando indicaram algumas ações Que achavam importantes para Qualificar o processo como maior cooperação entre discentes e docentes, elaboração de metas conjuntas, retorno das informações, maior discussão, avaliação de disciplinas no decorrer do ano, avaliações não serem realizadas por professores Que ministram aula na série Que está se submetendo a avaliação.

\section{Os Pressupostos Teóricos na Voz dos Docentes do Curso de Enfermagem}

$\mathrm{Na}$ elaboração do formulário para coleta de dados com os docentes consideramos, da mesma forma Que com os discentes, os conceitos Que compunham os pressupostos teóricos do PPP do curso de enfermagem. Nele foram formuladas as seguintes Questões: 1) Fale sobre o conceito de homem que você aborda em sua disciplina; 2) Como é abordado o conceito de trabalho e processo de trabalho em sua área; 3) Explicite como você tem abordado a idéia de humanização em sua prática docente; 4) Como você avalia a noção de interdisciplinaridade na organização curricular e na sua atuação docente; 5) Fale sobre a concepção de saúde/ doença Que tem perpassado sua atuação docente; 6) Como você tem definido e abordado o conceito de enfermagem e enfermeiro 
(a) em sua atuação docente; 7) $\mathrm{O}$ Que significa, em seu entendimento uma formação generalista, crítica e reflexiva; Em relação à construção e avaliação do Projeto Político Pedagógico do curso de enfermagem: 8) Se você participou da construção elabore uma reflexão sobre aquele processo; 9) Como você tem vivenciado o processo de avaliação do atual Projeto Político Pedagógico? Que ações você considera necessárias para Qualificar a avaliação?

Ao nos reportarmos ao conceito de homem explícito no PPP já citado acima nota-se Que concretamente há aproximação com a abordagem dos docentes, visto que as falas abordam o homem como ser histórico-social, Que pensa, tem uma linguagem e uma cultura, Que determina em certa medida e é determinado pelo ambiente Que está inserido e Que supre suas necessidades agindo sobre a natureza.

As falas docentes Quanto ao conceito de trabalho convergiram para uma atividade essencial realizada intencionalmente pelo homem, por meio da Qual transforma a natureza para satisfazer suas necessidades e garantir sua sobrevivência, não se afastando do referenciado no PPP.

O processo de trabalho abordado no PPP se configura, "na atuação do homem sobre um determinado objeto, tendo em mente uma finalidade pré-determinada e utilizando-se para isso de instrumentos tais Que permitam modificar esse objeto conforme suas necessidades" (3:5). Quando comparado este conceito com as respostas dos docentes verificamos Que a maioria destas se assemelham ao propugnado no PPP, principalmente no Que se refere à utilização de meios/instrumentos e estabelecimento de uma finalidade.

$\mathrm{Na}$ idéia de humanização relatada pelos docentes verificamos Que o principal ponto de convergência das falas foi o mesmo Que se aproxima da concepção de humanização defendida no PPP. Este ponto se refere à ação não somente de cunho individual, mas também a inclusão de estratégias Que busQuem a Qualificação da assistência e atendimento das necessidades dos usuários. No entanto, se faz indispensável a participação popular, vínculo profissional-usuário, fortalecimento da equipe de trabalhadores e políticas de saúde adeeuadas.

$\mathrm{Na}$ avaliação da interdisciplinaridade na atuação docente e na organização curricular as respostas denunciaram a presença de fragmentação dos campos de conhecimento e distanciamento entre as áreas, a falta de relação entre disciplinas e a profissão, a existência da tentativa de rompimento da especialização, a concepção de interdisciplinaridade como um método de ensino e a prevalência da multidisciplinaridade.

Quanto à concepção do processo saúde/doença houve um discurso generalizado enfocando os fatores ambientais, sociais, econômicos, culturais Que interferem no processo e que este reflete o modo como a sociedade se organiza.

Assim podemos afirmar a existência de uma convergência acentuada entre o conceito do PPP e o expresso pelos docentes. Visto Que este entendimento propicia o repasse de conhecimentos mais concretos resultando na prestação de assistência Que atenda/ resolva de fato as necessidades e problemas da sociedade, além de ir ao encontro com um dos objetivos do curso de enfermagem, Que é formar enfermeiros motivados a intervir nos problemas de saúde da população, considerando os fatores sócio-econômico-político e culturais Que influenciam o processo saúde/doença”(3).
Os docentes abordaram a enfermagem como uma profissão nova, construída historicamente, uma prática social e política, ciência, comprometida com a prevenção de doenças, a promoção e recuperação da saúde. E o enfermeiro como profissional da saúde integrante e coordenador de uma equipe, com competência administrativa, política, assistencial e de ensino. Entendimentos Que se convergem ao conceito de enfermagem do PPP.

Conforme o conceito de formação generalista presente no PPP, citado anteriormente, percebemos Que a percepção dos docentes se aproxima, uma vez Que aparece nas falas, o conhecimento necessário para atuação em diversos campos de trabalho sem uma especialidade, a compreensão dos principais problemas que atingem a população a partir do perfil epidemiológico e sem determinado enfoque para áreas especificas.

Segundo os docentes formação crítica reflexiva se refere à capacidade de analisar, discutir, diagnosticar necessidades da população, emitir opinião, agindo a partir de seus princípios e valores. Traçando um paralelo desta compreensão com o perfil do profissional crítico e reflexivo do PPP nota-se Que há concretamente uma aproximação de conceitos.

$\mathrm{Na}$ Questão Que requer uma reflexão do processo de desenvolvimento do Projeto Político Pedagógico do curso de enfermagem houve o apontamento para aspectos Que tornam o processo de construção e avaliação limitado; dentre eles destacase a pouca adesão dos professores; o não tornar prático o acordado no coletivo; a idéia do PPP como apenas conteúdo teórico; as especialidades e a dicotomia Que ainda estão presentes. Entretanto, características que fomentam este processo também foram citadas, como "processo rico", "importante, pois prezou pela discussão coletiva", "processo em contínua implementação, (re) estruturação e reflexão na medida em Que é "caminhando que se faz o caminho", "processo de grande valor para os rumos da formação do enfermeiro", "reformulação Que contou com o maior número de pessoas envolvidas".

As ações consideradas necessárias para Qualificar a avaliação remetem a participação dos docentes e discentes, o retorno de informações, a discussão de aspectos da administração e gestão Que interessam no processo de produção de conhecimento e a institucionalização deste processo.

\section{CONSIDERAÇÕES FINAIS}

Como foi assinalado anteriormente, a pesquisa se propôs a analisar e discutir a mudança curricular de um curso de enfermagem na Região Oeste do Paraná em Que observamos Que é feito um esforço pela construção do processo de formação em espaço coletivo. Entretanto, os dados mostraram Que esta construção ainda não conseguiu inserir todos os sujeitos (docentes e discentes), pois identificamos Que não há, efetivamente, a participação de todos no processo. Importantes experiências de reformas curriculares podem ser averiguadas na Revista Brasileira de Enfermagem em seu volume 56, número $4^{(4)}$.

O curso se organiza em uma estrutura disciplinar o Que não inviabilizaria a articulação entre as diferentes disciplinas se entendermos Que o processo ensino aprendizagem se constitui na articulação de conteúdos, na presença insubstituível do professor e na participação dos discentes, sem deixar de contextualizar com 
a realidade e exigir esforço do aluno na busca de novos conhecimentos. Partimos do pressuposto de Que o professor não é meramente expositor e transmissor de conhecimento aos alunos, Que vão recepcionando, "guardando", mas indivíduo dotado de experiências e habilidades; Que repassa aos alunos conhecimentos na perspectiva de Que haja articulação com as áreas do conhecimento, elaboração de concepções lógicas, racionais, críticas e reflexivas.

Queremos indicar Que não é a estrutura disciplinar Que atribui ao discente a característica de ser passivo e apenas receptivo, "acrítico". Pensamos que a estrutura disciplinar adotada pelo curso em seu PPP, longe de fomentar estas posturas requer que o discente tenha papel central, uma vez Que se defende a formação crítica e não apenas a reprodução daQuilo Que foi abordado pelo professor.

O PPP implantado em 2003 destaca-se pelo seu aprimoramento e inserção de conceitos e pressupostos o Que em projetos anteriores não se evidenciava, citam-se os conceitos de homem, humanização, interdisciplinaridade, trabalho, processo de trabalho, enfermeiro, enfermagem, formação generalista, crítica e reflexiva. Também se notam alterações de ordem estrutural como carga horária, ementas, desmembramento de disciplinas, sem, contudo abandonar a estrutura disciplinar e objetivar a formação Qualitativa do profissional.

A partir do entendimento de Que os pressupostos teóricos norteiam o processo de formação e Que concentraram a maior parcela de alterações comparando com o PPP anterior, achamos pertinente identificar em Que medida eles estão presentes na prática docente e discente e, conseqüentemente diferenciando a formação profissional.

A partir do processo de análise concluímos Que os conceitos de homem, processo saúde/doença, trabalho, formação generalista estão fazendo parte da prática docente e sendo assimilados pelos discentes, uma vez que suas abordagens se aproximaram do proposto no PPP.

Quanto à concepção de humanização comparando-se as respostas de docentes e discentes percebemos Que houve pontos de convergência, no Que diz respeito ao cuidado por natureza, o respeito à individualidade e o tratar bem. No entanto, o aspecto mais enfatizado pelos docentes (ação Que envolve Qualificação da assistência, autonomia, políticas de saúde adequadas, vínculo profissional-usuário), presentes no PPP do curso foi minimamente pautado pelos discentes. Pensamos Que isto se deve ao fato de que o discente, apesar de ter uma visão até abrangente da humanização, no contexto de sua formação, não tem conseguido articular sua atuação com o contexto da saúde e do papel Que desenvolverá não só como executor, mas como propositor de políticas e práticas humanizadas. Para tanto, talvez a prática docente e o processo de formação não estejam conseguindo materializar o proposto.

Evidenciou-se Que tanto para os alunos Quanto para os docentes a interdisciplinaridade não está se estruturando no curso, havendo divergência do conteúdo teórico com a prática. Percebe-se Que há tentativas isoladas e não coletivas para a adoção efetiva deste conceito, isto nos leva a pressupor Que temos uma orientação no Projeto Político Pedagógico Que se tornou apenas conteúdo teórico e Que falta maior pactuação por parte dos professores em seguir o PPP, e dos alunos em cobrar a articulação com outras áreas. Além de Que, nos espaços de discussão coletiva, alunos e docentes devem pensar formas e estratégias Que garantam a materialização deste princípio.

No processo de análise evidenciamos Que os professores avaliam Que a interdisciplinaridade está restrita e fragmentada o Que não significa Que acham dispensável para sua prática docente, uma vez Que alguns acreditam e a defendem para a formação Qualificada do profissional. Para tanto, as estratégias Que potencializem o envolvimento efetivo de docentes e discentes são urgentes.

A formação crítica e reflexiva descrita pelos discentes não se aproxima em todos os aspectos com o conceito do PPP. Ela evidenciou-se na tomada de decisões, na identificação de soluções para problemáticas da assistência e no trabalho profissional. Mas, Quando analisamos a abordagem feita pelos docentes, se evidencia concretamente uma convergência para o PPP e isto pode nos indicar Que há um desencontro entre o Que pensam os docentes o Que propõe o PPP e o Que efetivamente tem sido internalizado pelos discentes.

Para se Qualificar e efetivar o processo de construção e avaliação do PPP ressaltamos a necessidade de maior envolvimento de docentes e discentes. Apesar de estes terem o conhecimento de Que o PPP norteia e Qualifica a formação do Enfermeiro, ainda demonstram passividade e desinteresse em participar.

Esperamos, Que de fato, este Projeto de Pesquisa tenha contribuído para o processo de discussão e avaliação do PPP, na medida em que identificou lacunas e equívocos a partir dos encaminhamentos dados à formação. Ressaltamos Que este processo, por ser dinâmico precisa ainda ser aprimorado, alguns aspectos precisam ser reavaliados e implementados para Que consigamos formar o profissional com o perfil Que se almeja.

\section{REFERÊNCIAS}

I. Rodrigues RM, Pereira RCF. Resgate histórico das alterações curriculares do Curso de Enfermagem da UNIOESTE/Campus de Cascavel, 1979-1999. Relatório final de Projeto de Pesquisa. Cascavel (PR): UNIOESTE - Centro de Ciências Biológicas e da Saúde-Colegiado do Curso de Enfermagem; 2001.

2. Saupe R, coordenador. Projeto Político Pedagógico dos Cursos de Enfermagem. Relatório Final. Florianópolis (SC): Universidade Federal de Santa Catarina; 2001.

3. Universidade Estadual do Oeste do Paraná. Projeto Político Pedagógico do Curso de Enfermagem. Cascavel (PR): UNIOESTE; 2003.

4. Revista Brasileira de Enfermagem. Rev Bras Enferm 2003; 56(4). 